\title{
MEASUREMENT OF THE LIFETIME OF $\mathrm{Pb}^{52+}, \mathrm{Pb}^{53+}$ and $\mathrm{Pb}^{54+}$ BEAMS AT 4.2 MeV PER NUCLEON SUBJECT TO ELECTRON COOLING
}

\author{
S. Baird, J. Bosser, C. Carli, M. Chanel, P. Lefèvre, R. Ley, R. \\ Maccaferri, S. Maury, I. Meshkov*), D. Möhl, G. Molinari, F. Motsch, H. \\ Mulder, G. Tranquille, and F. Varenne \\ CERN, 1211 Geneva 23, Switzerland \\ *) Permanent affiliation: JINR, Dubna, Russia
}

\begin{abstract}
By measuring the lifetime of stored beams, the recombination of the ions with cooling electrons was investigated. Rates found are larger than expected for radiative electron capture and significantly higher for $\mathrm{Pb}^{53+}$ than for $\mathrm{Pb}^{54+}$ and $\mathrm{Pb}^{52+}$. These results are important for the design of the lead ion injection system for the Large Hadron Collider and for recombination theories.
\end{abstract}

When electron cooling [1] is applied to heavy ions, recombination i.e. capture of cooling electrons into atomic levels resulting in losses of ions from the storage ring due to the change of their charge [2] - can become important. We have determined the recombination rates of partially stripped lead ions by storing and cooling beams from a recently commissioned linac [3] in the Low Energy Antiproton Ring (LEAR) (Table 1) to test its feasibility as a Low Energy Accumulator Ring for ions [4]. Rate coefficients were derived from the beam lifetime as a function of the electron current.

Table 1 - Parameters of the experiment

\begin{tabular}{|lcc|c|}
\hline Ion energy & $\mathrm{E}$ & {$[\mathrm{MeV} / \mathrm{u}]$} & 4.2 \\
\hline Velocity (of ions and electrons) & $b=\mathrm{v} / \mathrm{c}$ & 0.094 \\
\hline Storage ring circumference $2 \pi \mathrm{R}$ & {$[\mathrm{m}]$} & 78.54 \\
\hline Storage ring vacuum pressure & $\mathrm{P}$ & toør $] ¥ 10^{-11}\left(85 \% \mathrm{H}_{2}\right.$ and $\left.\mathrm{He}\right)$ \\
\hline
\end{tabular}




\begin{tabular}{|c|c|c|c|c|}
\hline \multicolumn{2}{|c|}{ Cooling length/circumference } & $h$ & & 0.02 \\
\hline Electron beam radius & $\mathrm{b}$ & {$[\mathrm{cm}]$} & & 2.5 \\
\hline Typical electron current & 1 & [A] & & $-0.2(0.4)$ \\
\hline \multicolumn{3}{|c|}{ e-density in cooling sectionn $n_{e}=1 / e \pi b^{2} b c$} & $\left.\mathrm{~cm}^{-3}\right]$ & $1.1 ¥ 10^{8}$ । \\
\hline \multicolumn{3}{|c|}{ Effective e-density per turnn $n_{\text {eff }}=h \mathrm{n}_{\mathrm{e}}\left[\mathrm{cm}^{-3}\right]$} & & $2.2 ¥ 10^{6}$ । \\
\hline \multicolumn{3}{|c|}{ Typical longit. B-field in cooler } & T] & 0.06 \\
\hline
\end{tabular}

The linac accelerates $\mathrm{Pb}^{27+*}$ which is further stripped by a foil after the exit. A "dogleg" arrangement of bending magnets and a "momentum defining slit" are used to select a single charge state. The transfer line and LEAR have also to be readjusted to inject and store different states. About equal intensities of $\mathrm{Pb}^{53}+$ and $\mathrm{Pb}^{5+}$ and $\mathrm{a}$ slightly $(\sim 20 \%)$ lower current of $\mathrm{Pb}^{52}+$ were found, in fair agreement with the results of Ref. [5].

The intensity of the circulating beam in LEAR (about $2 \mu \mathrm{A}$ corresponding to $\approx 5 ¥ 10^{5}$ ions at injection) was monitored via the Schottky noise [6], observed with current pick-up electrodes. A typical scan, giving the evolution of the beam current, is shown in Fig. 1. The $1 /$ e lifetime $(t)$ is obtained from an exponential fit. Decay rates $(1 / t)$ as function of the electron current are drawn in Fig. 2. From the slope of the curves, rate coefficients $a=\left\langle s v_{\text {rel }}\right\rangle=(1 / t) / \mathrm{n}_{\text {eff }}$ (i.e. the decay rates normalised to the effective electron density $h_{\text {eff }}$, Table 1$)$ are derived. They are collected in Table 2.

Table 2 -Rate coefficients. Present results and values reported in the literature for partially stripped uranium and gold ions. Included for comparison are the rates calculated for radiative capture from Bell's formula [7] taking an electron temperature $\mathrm{T}_{\mathrm{e} \perp}=0.2 \mathrm{eV}$ and an effective ion charge $\mathrm{Q}_{\mathrm{eff}}=(\mathrm{Q}+\mathrm{Z}) / 2 \quad[8]$.

\begin{tabular}{|l|c|l|c|}
\hline Ion & $\begin{array}{c}\text { Measured rate } \\
\text { coefficient } \\
\text { a }\left[10^{-8} \mathrm{~cm}^{3} \mathrm{~s}^{-1}\right]\end{array}$ & Reference & $\begin{array}{c}\text { Calculated from } \\
\text { Bell's formula } \\
\text { for radiative } \\
\text { capture } \\
\mathrm{a}\left[10^{-8} \mathrm{~cm}^{3} \mathrm{~s}^{-1}\right]\end{array}$ \\
\hline
\end{tabular}

\footnotetext{
* We use $\mathrm{Pb}^{\mathrm{Q}}+$ to denote lead ions (atomic charge number $\mathrm{Z}=82$ ) of charge state $\mathrm{Q}$, i.e. with $\mathrm{Z}-\mathrm{Q}$ remaining electrons.
} 


\begin{tabular}{|l|c|c|c|}
\hline $\mathrm{Pb}^{52+}$ & 11 & $\begin{array}{c}\text { present results } \\
\text { (June 95) }\end{array}$ & 2.25 \\
\hline $\mathrm{Pb}^{53+}$ & 60 & $"$ & 2.29 \\
\hline $\mathrm{Pb}^{54+}$ & 9 & $"$ & 2.32 \\
\hline $\mathrm{U}^{28+}$ & 10 & {$[8,9,11]$} & 1.8 \\
\hline $\mathrm{Au}^{25+}$ & 10 & {$[9]$} & 1.3 \\
\hline
\end{tabular}

Two interesting facts emerge from this table: The rate coefficients are larger than calculated for radiative electron capture (using e.g. Bells' formula [7]) and the contrast between $\mathrm{Pb}^{53}+$ and the neighbouring charge states is very striking. The difference between $\mathrm{Pb}^{52+}$ and $\mathrm{Pb}^{54+}$ is not very significant given the error $( \pm 15 \%)$ of the measurement.

"Anomalously" high recombination rates have recently been found [8-11], with electron cooling or in a single pass technique with a comoving "electron target", for a few special ions (Table 2). But this is the first time that neighbouring charge states of the same element were investigated with electron cooling showing a marked difference in the capture cross section.

Attempts reported in the literature to explain the "anomalous" recombination by dielectronic capture [2, 8-11] are so far only partially successful. Thus after a careful examination of the possible resonances Ref. [11] concludes that the "... recombination rate of $\mathrm{U}^{28+}$ ions... still remains a mystery." We have no explanation to offer for the higher rate of $\mathrm{Pb}^{53}+$ except the observation that $\mathrm{Pb}^{54+}$ and $\mathrm{Pb}^{52}+$ can perhaps arrange their remaining 28 and 30 electrons in closed shell structures (e.g. K, L, $M$ shells for $\mathrm{Pb}^{54+}, \mathrm{K}, \mathrm{L}, \mathrm{M}$ plus $\mathrm{N}$, s-subshell for $\mathrm{Pb}^{52+}$ ) whereas $\mathrm{Pb}^{53+}$ with its odd number of electrons does not have this possibility.

The motivation for the present study is the need for dense bunches of lead ions for the future Large Hadron Collider (LHC) [12]. Our results indicate that $\mathrm{Pb}^{54}$ (or $\mathrm{Pb}^{2+}$ ) is well suited for accumulation and electron cooling during a few seconds at $4.2 \mathrm{MeV} / \mathrm{u}$, as proposed for the lead injection system of the LHC [4], whereas $\mathrm{Pb}^{53+}$, originally foreseen, has an uncomfortably short lifetime in the presence of strong electron cooling.

\section{ACKNOWLEDGEMENTS}


We are indebted to our colleagues from the Linac, RF and Vacuum Groups and to the LEAR Operation technicians for their special efforts for this experiment.

\section{REFERENCES}

[1] H. Poth, Physics Reports 196, (1990) 135.

[2] H. Beyer, D. Liesen and O. Guzman, Part. Acc. 24 (1989) 163,

A. Müller, Electron-ion recombination phenomena, in: Proc. Workshop on Recombination of Atomic Ions (Newcastle, 1991), eds. W. Graham et al. (Plenum Press, New York, 1992) p. 155.

[3] D.J. Warner, Heavy Ion Linac for the CERN lead ion facility, in: Proc. 1994 Linac Conf. (Tsukuba), Vol. 2, eds. T. Takata, W. Yamazaki and K. Nakahara, p. 654.

H. Haseroth, The CERN heavy ion accelerating facility, in: 1995 Part. Acc. Conf. (Dallas), to be published.

[4] P. Lefèvre and D. Möhl, Lead ion accumulation scheme for LHC, in: Proc. Workshop on Beam Cooling and Related Topics (Montreux, 1993), ed. J. Bosser (Report CERN 94-03, 1994) p. 411, see also Report CERN-PS 93-62/LHC Note 259 (1993), unpublished, and

S. Baird et al., CERN PS/AR/Note 95-06 (MD) (1995), unpublished.

[5] E. Baron, M. Bajard and C. Ricaud, Nucl. Instr. Methods A238 (1993) 117.

[6] D. Boussard, Schottky noise and beam transfer function diagnostics, in: Proc. CERN Accel. School (Oxford, 1985), Vol. 2, ed. S. Turner (Report CERN 87-03, 1987) p. 416.

[7] K. Kilian and D. Möhl, Lecture Notes in Phys. 178 (1983) 163.

[8] A. Müller et al., Physica Scripta T37 (1991) 62.

[9] A. Müller et al., Radiative and dielectronic recombination, in: Proc. Symposium on Cooler Rings (Tokyo, 1990), eds. T. Katayama and A. Noda (World Scientific, London, 1991) p. 248.

[10]A. Wolf et al., Electron-ion recombination in merged beams, in: Proc. 13th Int. Conf. on Atom. Phys. (Munich, 1992), eds. H. Walther et al. (AIP Conf. Proc. Vol. 275, Am. Inst. Phys., New York, 1993) p. 228. 
[11]0. Uwira et al., in: GSI Scientific Report 94, ed. U. Grundiger, (Report GSI 94-1, March 1995, p. 137).

[12]The LHC Study Group, eds. Y. Baconnier et al., Report CERN/AC/9303 (LHC) (1993). 


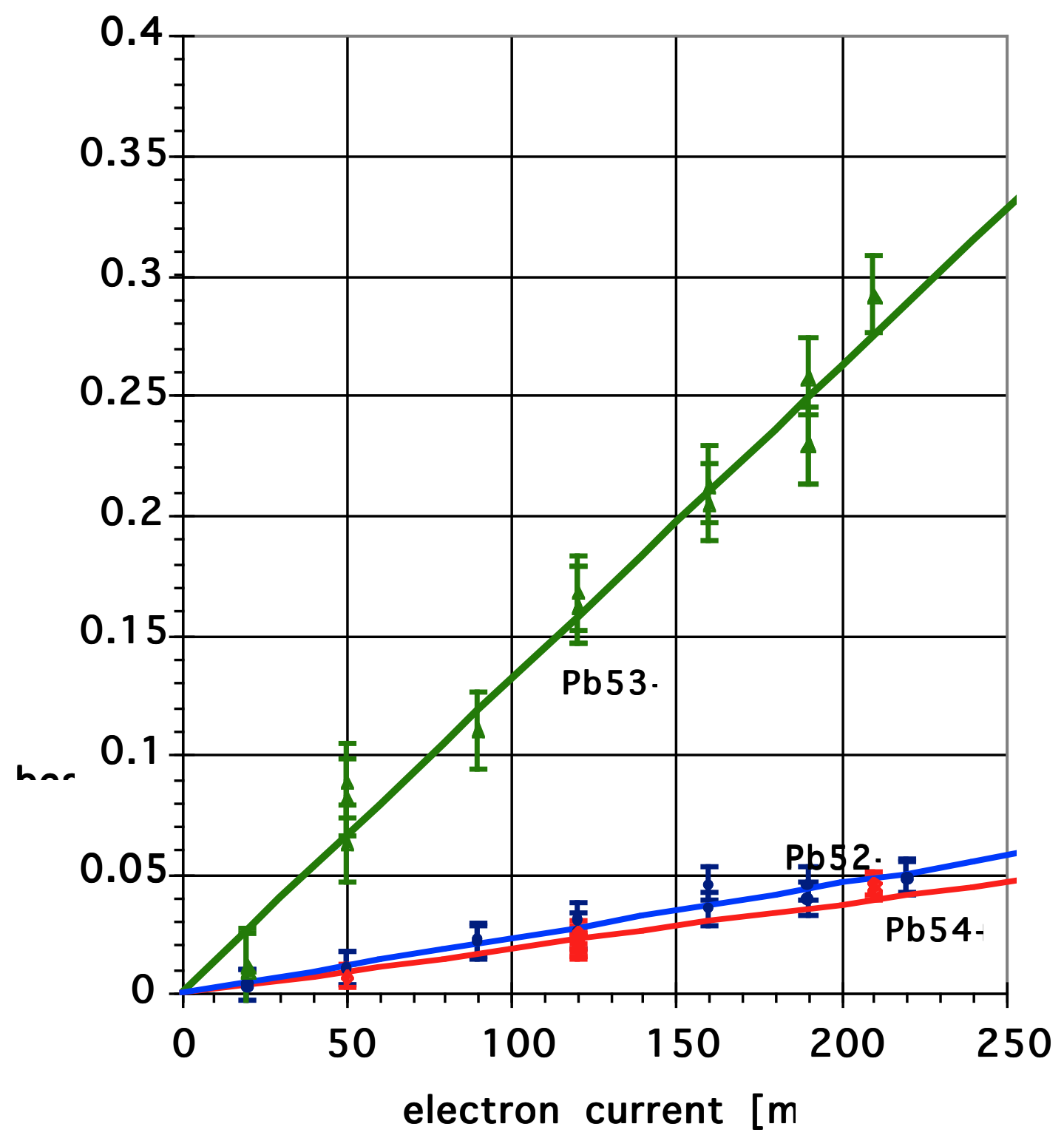

Fig. 1. Beam Schottky noise at the $100^{\text {th }}$ harmonic ( $\mathrm{f} \approx 36 \mathrm{MHz}$ ) of the revolution frequency, as displayed by a spectrum analyzer used in the receiver mode to record the time evolution of the signal induced on a beam current pick-up electrode. The resolution bandwidth $(30 \mathrm{kHz})$ of the analyzer is chosen to cover the full frequency spread given by the momentum width of the cooled beam i.e. the total noise in the band is recorded. The scan is triggered to start $0.2 \mathrm{~s}$ prior to injection and the evolution of the signal is shown during about $10 \mathrm{~s}$. The electronic noise $(\mathrm{N})$ of the acquisition system adds in square to the Schottky signal (S). Thus the voltage recorded by the analyzer is $\mathrm{U}(\mathrm{t})=\sqrt{S^{2}(t)+N^{2}}$. The decay rate is deduced from an exponential fit of the Schottky power $\mathrm{S}^{2}(\mathrm{t})$, which is proportional to the ion beam current. In this example the measurement for a $\mathrm{Pb}^{53+}$ beam at $120 \mathrm{~mA}$ electron cooling current is displayed. 


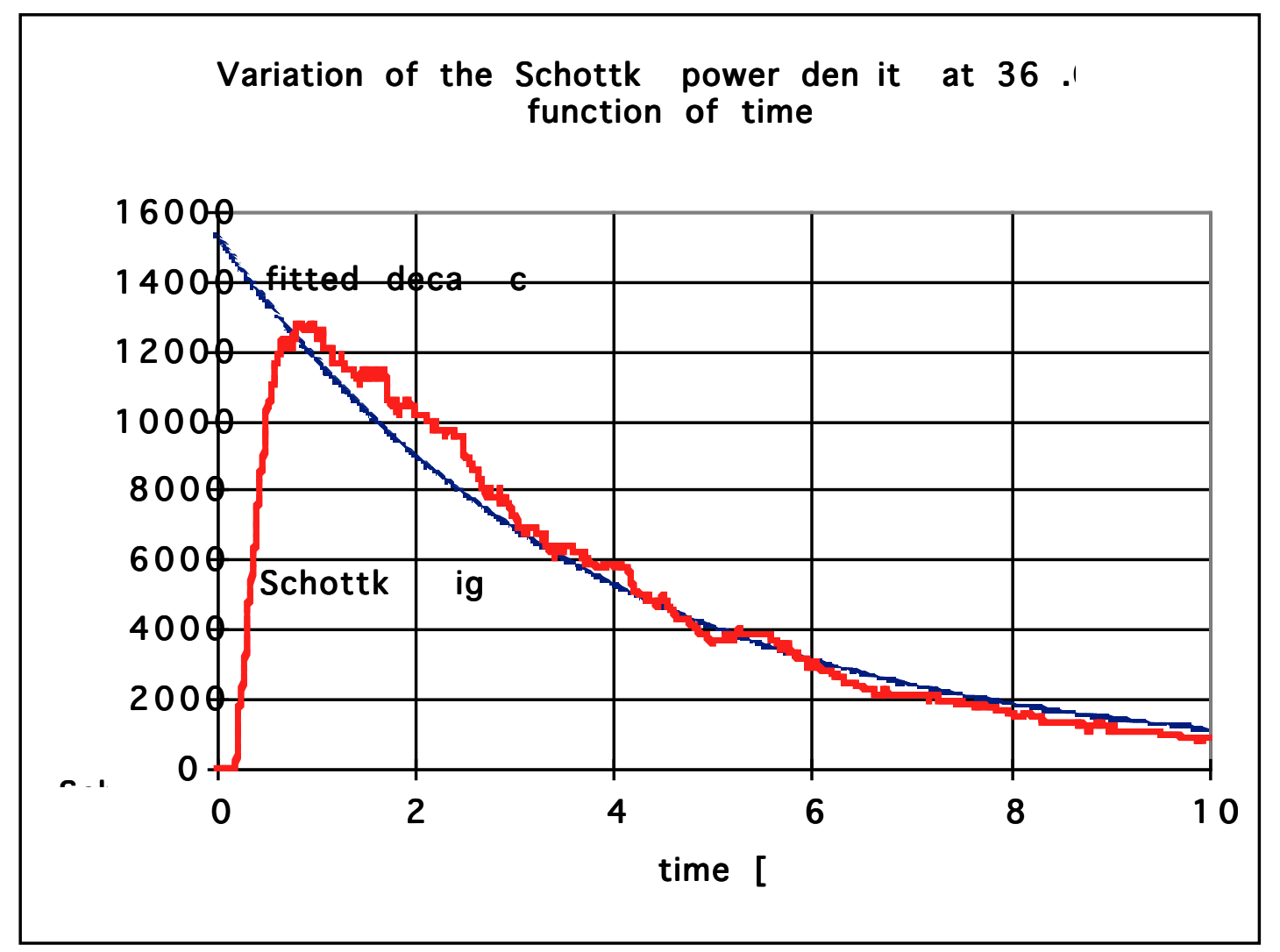

Fig. 2.Beam decay rates $1 / t$ as a function of the electron cooling current. A constant "background" of $1 / t \approx 1 / 20 \mathrm{~s}$, corresponding to charge exchange with the residual gas, has been subtracted from the data. The rate coefficients given in Table 2 are deduced from the slope of the curves. 